\title{
Desvío y debilitamiento en la búsqueda narrati- va de Silvina Ocampo
}

\author{
Judith PODLUBNE \\ Universidad Nacional de Rosario-CONICET. Argentina
}

\begin{abstract}
RESUMEN
Los comienzos narrativos de Silvina Ocampo se leyeron por lo general desde una perspectiva evolutiva que reconoce en Autobiografia de Irene, su segundo libro de relatos, un momento de desarrollo y perfeccionamiento de las "falencias", "defectos" e "imprecisiones" formales y estilísticas que habrían caracterizado los cuentos iniciales de Viaje olvidado. En desacuerdo con esta perspectiva, que reduce la singularidad del primer libro de Ocampo y valora de un modo positivo las transformaciones que presentan sus relatos posteriores, este trabajo propone y argumenta la idea de que en Autobiografía de Irene la singular búsqueda narrativa que la literatura de Silvina Ocampo desencadena en Viaje olvidado se desvía de los propósitos inmanentes que la impulsan para orientarse en un sentido ajeno y exterior a los mismos, en el que se debilita notablemente su fuerza de invención inicial.

Desde mi punto de vista, el volumen exhibe el modo en el que la literatura de Ocampo se torna sensible a las distintas demandas y exigencias del contexto inmediato: por un lado, las transformaciones técnicas y temáticas que estos cuentos incorporan responden a los valores estéticos que Borges y Bioy proclaman en el interior de Sur, por otro, los cambios que ellos registran a nivel de la sintaxis oracional, en particular, y de la lengua, en general atienden a las objeciones que Victoria Ocampo expuso en su conocida reseña al primer libro de Silvina.
\end{abstract}

Palabras clave: Autobiografía de Irene, Silvina Ocampo, desvío, debilitamiento, búsqueda narrativa.

\section{Diversion and weakening in Silvina Ocampo's narrative search}

\begin{abstract}
Silvina Ocampo's narrative beginnings were read, in general, from an evolutionary perspective which she acknowledges in Autobiografia de Irene, her second book of short-stories, as a moment of development and improvement of the formal and stylistic "fallacies", "faults" and "vagueness" that would have characterized the initial tales of Viaje Olvidado. Disagreeing with this perspective that reduces Ocampo's first book singularity and values in a positive way the transformations present in her later short-stories, this work suggests and argues the idea that in Autobiografia de Irene the singular narrative search that Silvina Ocampo's literature triggers in Viaje Olvidado diverts from the immanent intentions that drive her to guide herself in an oblivious and external sense, in which its strength and initial invention weaken notably.

From my point of view, the volume shows the way in which Ocampo's literature turns sensitive to the different demands and requirements of the immediate context: on the one hand,
\end{abstract}


the technical and thematic transformations that are found on these tales respond to the aesthetic values that Borges and Bioy proclaim in the interior of Sur (South), on the other hand, the changes that they register at the syntactic level in particular, and in language in general, meet the objections that Victoria Ocampo showed in her well-known review of Silvina's first book.

Keywords: Autobiografía de Irene, Silvina Ocampo, Detour, Weakens, Narrative research.

Publicado en 1948, once años después de Viaje olvidado, el primer libro de la autora, Autobiografia de Irene reúne algunos de los relatos que Silvina Ocampo escribió a lo largo de la década del cuarenta. "Epitafio romano", el cuento que encabeza el volumen, se había publicado inicialmente en el diario La Nación, en septiembre de 1943, y "Autobiografía de Irene", el relato que le da nombre a la colección, y "El impostor", la nouvelle que ocupa más de la mitad del libro, habían aparecido en los números 117 (julio 1944) y 164-165-166 (junio-julio, agosto y septiembre 1948) de la revista Sur. "La red" y "Fragmentos de un libro invisible" fueron los únicos inéditos hasta ese momento. A diferencia de la cantidad de relatos breves y de anécdotas mínimas que integran Viaje olvidado, Autobiografía de Irene se compone de cinco narraciones extensas y de asuntos complejos. Sin dudas, tal como lo señaló la crítica, el libro manifiesta la adhesión de esta narrativa a la prédica de Borges y Bioy. Pero antes que esta adhesión -digo "antes" porque se trató justamente de una condición de posibilidad para que esta identificación se realizara, exhibe el modo en el que la literatura de Ocampo se torna sensible a las distintas demandas y exigencias del contexto inmediato. No sólo porque las transformaciones técnicas y temáticas que incorporan estos relatos (y de las que voy a ocupar en detalle más adelante) responden a los valores estéticos que Borges y Bioy proclaman en el interior de Sur, sino también porque los cambios que los cuentos registran a nivel de la sintaxis oracional, en particular, y de la lengua, en general (pienso, por ejemplo, en la forma en que el léxico culto y las referencias eruditas desplazan por completo los giros coloquiales y las imágenes inusitadas, acusadas de mal gusto, que recorren Viaje olvidado) atienden en cierta forma a las objeciones que Victoria expuso en su célebre reseña sobre el libro inicial de Silvina.

En Autobiografía de Irene la singular búsqueda narrativa que la literatura de Ocampo desencadena en Viaje olvidado se desvía de los propósitos inmanentes que la impulsan para orientarse en un sentido ajeno y exterior a los mismos, en el que se debilita notablemente su fuerza de invención inicial. El libro puede leerse, en primera instancia, como una respuesta demorada al desafío con que su hermana le abre las puertas del reconocimiento literario.

El Viaje olvidado -concluye Victoria en su reseña (1937: 121)- es un primer libro en que encontramos cualidades y defectos equivalentes. Estos defectos ison el reverso indispensable de las cualidades? ¿Sería posible aumentar las unas y dis- 
minuir las otras? Sólo Silvina Ocampo puede contestar a estas interrogaciones dándonos un nuevo libro.

La interpelación proyecta sus efectos intimidatorios más allá de Viaje olvidado: no sólo liga el debut narrativo de Silvina a los presuntos "defectos" de este libro, sino que además condiciona el futuro literario de la escritora a la superación de estas insuficiencias. Una interpelación severa y fuertemente moral -amparada en las virtudes morales del "escribir bien"- a la que Silvina reacciona con cierta timidez y acatamiento, por vías distintas aunque relacionadas. En 1942, aparece su próximo libro, Enumeración de la patria: los incómodos relatos de Viaje olvidado ceden su lugar a una colección de poemas de temas nacionales y universales, escritos en una lengua poética instituida, atada a pautas líricas tradicionales. A este libro, que recibe dentro y fuera de Sur una inmediata acogida favorable (además de la elogiosa reseña de Borges, Silvina obtiene el Premio Municipal de Poesía), le sucede, en 1945, Espacios métricos, otro libro de poemas igualmente moldeados sobre pautas convencionales. ${ }^{1}$ Como en mucha de su poesía posterior, en estos poemas, señala Nora Avaro (2004),

la imaginación, facultad esencial en la preceptiva artística de Ocampo, se debilita [...] y en ese lugar casi vacante, se activa la destreza y la disciplina propias del entrenamiento versificador. La cierta agramaticalidad de su prosa, fundamentalmente, la de sus primeros y magníficos relatos de Viaje olvidado, revierte en el cambio de género, en una discreta apostura del verso.

La misma pérdida de la potencia imaginativa ligada al esfuerzo retórico y disciplinador por acogerse a fórmulas consolidadas signa las transformaciones que manifiestan los cuentos de Autobiografía de Irene.

Luego de una larga década de tortuosas vacilaciones e inquietudes en torno a su escritura -vacilaciones de las que su correspondencia con Bianco brinda testimonios repetidos ${ }^{2}-$ Silvina publica su segundo libro de relatos. El ingreso a la poesía incide en su consideración sobre las posibilidades de un lenguaje más reflexivo y elaborado. ${ }^{3}$ Una lengua literaria convencional y trabajada, en la que no se aventuran

\footnotetext{
${ }^{1}$ Para el análisis de estos libros de Ocampo, consultar los estudios de Percas (1954) y Ulla (1992).

2 Pueden consultarse estas cartas en la Colección José Bianco. División Manuscritos, Departamentos de Libros raros y Colecciones Especiales de la Universidad de Princeton (New Jersey-USA).

${ }^{3}$ La reseña que Carmen Gándara dedica a Autobiografía de Irene se inicia con una extensa digresión sobre las virtudes comunicativas de la "Poesía" e inscribe a los cuentos de este libro en esa tradición. "Su lenguaje, en el que se cumple una consciente y elaborada naturalidad, -afirma- es un lenguaje que refleja las cosas en su ser, y no sólo refleja las
} 
aún los riesgos y los excesos en que su prosa incurrirá a partir de La furia y otros cuentos (1959), reemplaza las anomalías sintácticas de Viaje olvidado. Antes que un perfeccionamiento o una maduración formal, las narraciones de Autobiografía de Irene presentan un notable cambio de registro, ligado a una evidente transformación en los temas, un aprendizaje esmerado hacia una lengua más estándar, más transparente y ajustada a las normas estilísticas, en la que contar historias intrincadas de dobles y clarividentes. ${ }^{4}$ Son relatos que exhiben el denodado y (en estos términos) exitoso esfuerzo que Ocampo realiza por responder a los mandatos lingüísticos y literarios instituidos en Sur -que no son, por supuesto y según vimos, sólo los mandatos que su hermana le impone sino los que Victoria misma comparte con una amplia mayoría de los miembros de la revista, entre ellos, algunos de los más cercanos a Silvina como son Bianco y el propio Bioy. Como señaló Matilde Sánchez (1991: 277) con agudeza, en estas ficciones

el lenguaje lleva la cadencia de la poesía [...]. Y precisamente la poesía, el trabajo con la lengua pero también una sensibilidad fundada en el desapego de lo cotidiano, permiten el recuerdo de lo que vendrá. Por eso, porque la prosa de la ficción y la presciencia se funda en la distancia, es éste el momento más "alto" de la narrativa de Ocampo, donde no hay lugar para la exageración que señalaba Molloy. La poesía, en Silvina, es sinónimo de métrica y norma literaria, de belleza y armonía, el reino de los supuestos universales de la tradición literaria.

Sin dudas Autobiografia de Irene es el momento más "alto", el más elevado, el artísticamente más logrado de toda su prosa, si se lo valora desde las pautas vigentes en Sur e incluso más allá de la revista, pero es también y, por las mismas razones, el menos intenso y singular de toda su obra narrativa. Esta es la conclusión que se anuncia en el comentario de Sánchez, que lee a Ocampo en la perspectiva ineludible y ya canónica que inauguraron los ensayos de Molloy. La voz extraña e inesperada que cuenta las historias iniciales y en la que se prefiguran muchos de los narradores posteriores ${ }^{5}$ se diluye en Autobiografia de Irene en manos de una conciencia estética advertida de la importancia de las convenciones y dispuesta a abrevar en el espacio compartido de la tradición literaria universal. No sólo en el espa-

cosas en su ser esencial, ideal, sino que las detiene; cada una de las figuras que evoca está detenida, mirándose en el cristal de una prosa que no quiere saber de movimientos ni de viajes temporales." (1949: 240).

${ }^{4}$ Acierta en este sentido Noemí Ulla cuando señala que es posible que los comentarios que Ocampo recibió sobre Viaje olvidado "hayan agudizado su autocrítica, su necesidad de ser solidaria con el castellano, de situarse en un registro común donde su gramática pudiera contextualizarse en la literatura argentina de esos años." (1982: 9)

5 Trabajé sobre los narradores de Ocampo en los relatos de La furia y otros cuentos y Las invitadas en Podlubne (2004). 
cio ya cronometrado de una lengua poética acompasada, armónica y de una belleza reconocible, sino también en el de las ficciones fantásticas que Ocampo contribuye a difundir en estos años junto a Borges y a Bioy. ${ }^{6}$

Una toma de conciencia literaria, estimulada por las objeciones y comentarios de quienes la rodean, despierta a Silvina de la inocencia estética del comienzo e imprime a sus relatos una fuerte torsión no sólo retórica sino también temática y compositiva, que los encauza en el marco de las morales literarias instituidas. Como las narraciones de Bianco, aunque sin la plena convicción con que él suscribe a estas exigencias hasta el final de su carrera literaria, Autobiografia de Irene responde tanto al imperativo de "escribir bien" como al de "construir bien". La búsqueda narrativa ocampiana se identifica en este punto con la idea de que la literatura es un objeto artificial, un sistema de convenciones que el buen escritor debe manejar con eficacia $^{7} \mathrm{y}$, adhiere transitoriamente -Ernesto Montequín acierta en designar este período como "un período de transición estética" (en Ocampo 2006: 295)- a la lógica compositiva que distingue a las "obras de imaginación razonada" (Borges 1940). Silvina concentra su máximo esfuerzo en la construcción rigurosa de argumentos complejos y recurre para ello a tópicos y procedimientos propios del género fantástico, e incluso, en el caso de "El impostor", del género policial, en el que se había ejercitado con Bioy un par de años antes escribiendo Los que aman, odian. Pero son sobre todo los modos de la representación fantástica los que apartan la escritura de Ocampo de la conmovedora e inaprensible rareza de los primeros cuentos y la orientan en dirección al calculado efecto de vacilación que provocan las narraciones de Autobiografia de Irene. La indiscernible ambigüedad que domina todos los niveles del relato en Viaje olvidado cede su lugar a la controlada e inteligente duplicidad que organiza los diferentes aspectos de estos cuentos. "Un principio de binarismo -señala Tomassini $(1995,42)$, a quien se le debe, también en este caso, el análisis de conjunto más exhaustivo que se realizó del volumen- gobierna el espacio del cuento, desde la configuración del proceso enunciativo hasta los posibles recorridos de lectura que el texto autoriza, pasando por el desdoblamiento de personajes en actantes opuestos o complementarios y la polifurcación de un acontecimiento en sucesivas versiones e inversiones."

Mientras la consigna de "volverse otra", que Jorge Panesi (2004) propuso como matriz especular de los relatos de Ocampo, alcanza en Viaje olvidado una resolución intensiva, en tanto su cumplimiento hace aparecer la diferencia irreductible que

${ }^{6}$ Sobre la participación de Ocampo en la Antología de literatura fantástica, Louis (en AAVV 1997) y Loustalet y Straccali (2001).

7 "El escritor -sostiene Bioy en el Prólogo a Antología de la literatura fantástica- deberá, pues, considerar su trabajo como un problema que puede resolverse, en parte por las leyes generales y preestablecidas, $\mathrm{y}$, en parte, por las leyes especiales que él debe descubrir y acatar." (1991: 6). 
liga a un personaje, a una voz o a un acontecimiento consigo mismo, en Autobiografía de Irene la realización de esta consigna se efectúa en un plano representativo en el que volverse otro significa ciertamente ser otro y, por tanto, la extrañeza propia de la alteridad queda circunscrita al territorio conocido del doble o de lo múltiple. Las distintas variantes que presenta la instancia enunciativa en estos cuentos se resuelve por lo general mediante la duplicación representada de las voces narrativas. El interrogante en torno al que se despliegan las historias se aleja de la pregunta inaugural de la literatura de Ocampo (¿Quién cuenta estos cuentos? ¿Quién habla en ellos?), para situarse en el marco de los acontecimientos extraños que conforma habitualmente el mundo de las ficciones fantásticas. Las tramas avanzan impulsadas por el interés en dilucidar el sentido de sucesos enigmáticos que, la mayoría de las veces, dan lugar a una multiplicidad de versiones diversas o contrapuestas. En "El impostor", que es junto a "Autobiografía de Irene" la narración más emblemática del volumen, aparecen dos narradores, representados y en primera persona, que asumen el relato de manera sucesiva y presentan diferentes explicaciones de lo ocurrido. Como en El perjurio de la nieve, de Bioy ${ }^{8}$ y como en Sombras suele vestir, de Bianco (aunque la narración está aquí a cargo de una voz en tercera persona que encarna las distintas perspectivas), esclarecer el sentido de los acontecimientos es una tarea que queda siempre en manos del lector. Uno y otro son textos con los que "El impostor" dialoga de un modo directo, a tal punto que los tres pueden considerarse como distintas variantes de un mismo ejercicio narrativo: el que busca conjugar las convenciones del fantástico con las leyes del policial y ambas con una reflexión metaliteraria sobre de las posibilidades del acto de leer.

El primer narrador de "El impostor" es Luis Maidana, un joven estudiante enviado a una estancia abandonada en Cacharí con el propósito de resolver "el misterio de [la] reclusión" de Armando Heredia. Luego de haberse recibido de bachiller en Europa y a punto de iniciar sus estudios de medicina, Heredia se encierra sorpresivamente en la estancia familiar y renuncia a su vida anterior. El padre le pide entonces a Maidana, hijo de uno de sus mejores amigos de la infancia, que pase unos días en el campo preparando sus exámenes, con la intención de que intente averiguar las razones que retienen al joven en el aislamiento y con la esperanza de que el contacto con él pueda influir favorablemente sobre su hijo. El relato de Maidana, cuya extensión ocupa casi la totalidad de la nouvelle, cuenta las difíciles alternativas de su estadía con Heredia. Es un relato saturado de indicios y alusiones, en el que el vínculo entre ambos jóvenes se

\footnotetext{
${ }^{8}$ Publicado inicialmente en 1945, en la colección "Cuadernos de la Quimera", e incluido luego en La trama celeste (Sur, 1948). En el prólogo La trama celeste que escribe para la reedición de 1967, Bioy cuenta que tenía pensado el argumento desde mucho antes. "En 1932, caminando por el barrio de La Recoleta, referí a Borges el argumento de "El perjurio de la nieve": una noche de insomnio, once años después, uní y até uno por uno los cabos sueltos, armé sin dificultad la historia y a la mañana me puse a escribirla." (1967: 8)
} 
describe, de un modo ambivalente, como una amistad recelosa, tensa y prevenida, hecha de confidencias mutuas y significativas complementariedades. Ambos se sienten atraídos por la que parece ser la misma mujer. Heredia no sueña, lo obsesiona la idea de no poder soñar, su psicoanalista le pidió en vano que escribiera sus sueños en un cuaderno; Maidana, en cambio, sueña mucho, confunde sus pensamientos con sus sueños, recuerda a menudo objetos y personas que vio en sueños anticipatorios. Maidana cree en la transmigración de las almas, en teorías sobre la reencarnación, Heredia es un escéptico. Una noche, luego de haber descubierto que Heredia está loco, que la mujer de la que está enamorado y con la cree encontrarse murió hace años, un sueño le anticipa su asesinato en manos del joven. Heredia descubre finalmente que Maidana es un espía de su padre y lo mata. Como en situaciones anteriores, la escena previa al crimen aparece duplicada en el relato: primero se cuenta la situación soñada, luego lo ocurrido. Todo es y no es en la narración de Maidana, todo se parece a otra cosa, recuerda a algo que sucedió antes; los personajes tiene una consistencia lábil y escurridiza: la casera y el peón de la estancia parecen "invisibles", Heredia aparece y desaparece de golpe, María Gismondi es y no es la muchacha que Maidana se encontró en el tren. Una declarada atmósfera de irrealidad, que Maidana describe una y otra vez, de distintas maneras, aunque nunca con el énfasis innecesario en que incurre al recordar los conocidos versos de Dante Gabriel Rossetti que Borges había invocado ya en el prólogo a La invención de Morel, contamina toda su versión de los acontecimientos.

El segundo narrador aparece en el momento del desenlace, inmediatamente después de que Maidana abandona su relato e intenta huir de Heredia. Se trata de Rómulo Sagasta, un amigo del padre de Heredia, cuya llegada a la estancia había sido anunciada al joven en una carta del padre. Sus "Consideraciones Finales" revelan el desenlace de la historia, que no es, tal como todo induce a considerar, el crimen de Luis Maidana sino el suicidio de Armando Heredia. Como ocurre con la presentación de la perspectiva de Julio Sweitzer en el final de Sombras suele vestir o, más aún, con la interpretación que Alfonso Berger Cárdenas plantea de la relación de Juan Luis Villafañe en $E l$ perjurio de la nieve, las consideraciones de Sagasta proponen una explicación nueva sobre los hechos narrados. Su discurso enmarca a posteriori la versión de Maidana e invierte su sentido: anuncia que el relato es en realidad el cuaderno titulado "Mis sueños", escrito por Heredia. "Armando Heredia -afirma Sagasta- sufría desdoblamientos. Se veía de afuera como lo vería Luis Maidana, que era a la vez su amigo y su enemigo" (Ocampo 1975: 89) ${ }^{9}$. Luego de algunas averiguaciones entre los amigos de Heredia en Buenos Aires y entre los conocidos en Cacharí, Sagasta descubre además que Maidana no existió nunca, que es un "ser imaginario" que Heredia inventó en su locura. La resolución, que, tal como advirtió Pezzoni (1986: 205) guarda un indudable parentesco con la de "Le voyageur sur la terre" de Julien Green, la nouvelle que Silvi-

${ }^{9}$ En adelante todas las citas de Autobiografía de Irene corresponden a esta edición, por lo tanto sólo consigno los números de páginas entre paréntesis. 
na Ocampo traduce en 1945 para "Cuadernos de la Quimera", no es sin embargo definitiva. La versión de Sagasta abre un último interrogante que deja abierto el desenlace de la historia.

\begin{abstract}
A veces pienso -afirma, en el final de sus consideraciones- que en un sueño he leído y he meditado este cuaderno, y que la locura de Heredia no me es ajena.

No hay distinción en la faz de nuestras experiencias; algunas son vividas, otras opacas; algunas agradables, otras son una agonía para el recuerdo; pero no hay como saber cuáles fueron sueños y cuáles realidad (90)
\end{abstract}

Además de mostrar una característica común a todos los narradores y personajes de Autobiografia de Irene, como es el carácter reflexivo, elaborado y, en algunos casos, sentencioso de sus voces (pienso, por ejemplo, en la voz profética que cuenta "Fragmento de un libro invisible"), estas observaciones plantean la alternativa de que sea Sagasta quien haya soñado todo lo sucedido, de que la historia de Heredia-Maidana sea el resultado de las perturbaciones psicológicas que sufre el propio Sagasta. ${ }^{10}$ En esta alternativa, "El impostor" presentaría en este caso una nueva variante del tópico del soñador-soñado, transitado por Borges en esos años: Heredia encarnaría la figura del hombre que sueña mientras es soñado por Sagasta. Como observa Tomassini (1995: 43) en tácita disidencia con Pezzoni, las conclusiones de este segundo narrador autorizan distintos modos de lectura del cuento, de acuerdo con modelos de género alternativos y no excluyentes entre sí: el del relato fantástico, el del psicológico y del policial, según se atienda al tema del doble, al de la locura o al del develamiento de las causas de la muerte suscitada. ${ }^{11}$ Si bien la ambigüedad de la historia permanece -para

${ }^{10}$ En su estudio sobre la relación entre tiempo y escritura en la obra de Silvina Ocampo, Annick Magin (1996), propone la existencia de un tercer narrador en "El impostor". Desde su punto de vista, la frase en itálica conque se cierra el cuento estaría fuera de las consideraciones de Rómulo Sagasta, no serían una cita o referencia a la que Sagasta recurre para cerrar su enunciado, sino que introduciría una nueva voz narrativa, que se agregaría a las dos señaladas. "Ce troisième narrateur -explica Magin (1996:148)- n'est pas identifié ni identifiable: il s'agit d'une instance extérieure qui tire une morale dont la nouvelle serait une illustration, une exemplum. Cette modalité d'écriture hétérogène créerait un troisième niveau d'enchâssement que le lecteur extra-narratif, encore une fois, ne peut percevoir que dans une visée rétrospective."

${ }^{11}$ Identificada con el rol de lector atento, activo y sagaz que postula este relato, Tomassini añade una posibilidad interpretativa adicional a las consideraciones finales de Sagasta: la de que él haya sido el asesino de Heredia. "Varias veces -explica (1995: 44)- se insiste en que la fecha de llegada de Sagasta a la estancia "Los cisnes" fue el 28 de enero de 1930. Hacia el final de su discurso, sin embargo, Sagasta comenta esta hipótesis: "Si yo hubiera llegado a 'Los cines' el 26 o el 27 de febrero en lugar del 28, como quería hacerlo, hubiera salvado con el fantasma de Maidana a Armando Heredia, pero tal vez habría perdido mi propia vida." Esta equivocación en una fecha tantas veces repetida en el texto no puede ser 
Pezzoni (1986: 205), por el contrario, el "documento" de Sagasta reduce la incertidumbre fantástica de la primera versión a una única explicación decepcionante- el hecho de que los distintos sentidos de la trama remitan a verosímiles precisos y específicos limita su indeterminación al efecto de ambigüedad deliberado, previsible $\mathrm{y}$, en última instancia delusorio, que, como señalé más arriba, caracteriza a los cuentos de este libro.

Los mismos procedimientos que Ocampo maneja en el final de "El impostor" componen los desenlaces de "Epitafio romano" y de "La red". En "Epitafio romano", la historia, situada en la antigüedad clásica, en la que el cónsul Claudio Emilio castiga la infidelidad de Flavia, su mujer, encerrándola y haciéndola pasar por muerta, explicita el mecanismo de los finales alternativos. El cuento propone tres desenlaces diferentes en el que coexisten sin resolverse distintas explicaciones de lo que sucede dos años después del encierro, cuando el protagonista lleva a la esposa ante su tumba y le permite leer su epitafio. Como anota Pezzoni (1986: 204), cada final se inscribe en un verosímil posible. En el primero, que es el que el narrador juzga como "el más previsible", en tanto se ajusta a las creencias y mandatos de la época, "Flavia agradece a Claudio Emilio la salvación del honor de sus hijos y de su familia por haberla ennoblecido prematuramente con los privilegios que sólo puede otorgar la muerte" (13). En el segundo, elaborado conforme al verosímil fantástico, un comentario de Flavia a su esposo ("[...] todos creen que he muerto, salvo tú: tú eres el único equivocado." (idem)) hace saber que ella es en efecto una aparición, un fantasma, e invierte el significado de la historia. En el último, el sentido se desplaza hacia el "relato de intriga" (Pezzoni, idem: 204). Flavia se reconoce indigna del privilegio de la muerte, Claudio Emilio parece arrepentirse de su venganza y busca en vano rectificar su decisión. Lleva a Flavia a su casa pero "nadie la reconoce y ella asegura ser una mendiga que un demente ha violado, después de vestirla con las túnicas que robó de una urna sagrada. La locura de Claudio Emilio es tal vez inevitable; nadie entiende sus explicaciones claras e ingeniosas [...]" (13-14). El procedimiento es ocurrente, pone en escena el carácter artificial de la elaboración estética, exhibe su condición de juego deliberado; su aplicación, esmerada y habilidosa, no alcanza sin embargo la pericia constructiva que presenta poco después en "El impostor". "Epitafio romano" se muestra en este sentido no sólo como el ensayo inicial de una técnica con la que Ocampo obtendrá luego mejores resultados sino también como el testimonio inicial de su arduo esfuerzo por adherir a la moral formalista del relato.

El desenlace de "La red", un cuento de naturaleza fantástica en el que se articulan dos de los motivos del género más utilizados en la literatura ocampiana: además del

casual: tal vez Sagasta, único enviado del padre de Heredia haya sido quien, creando el fantasma de Maidana, terminara asesinando a Heredia. Lectura coherente dentro del paradigma del "relato policial", que el texto autoriza." 
tópico del doble, el de la metamorfosis ${ }^{12}$, postula la alternativa final de que todo lo narrado hasta ese momento resulte un sueño. Como en "El impostor", también en este relato la instancia enunciativa se encuentra duplicada: una narradora anónima introduce, comenta muy poco y cierra la historia que su amiga Kêng-Su le está contando. La historia de Kêng-Su, que guarda algunas similitudes con el microrelato de Chuang Tzu, recogido en la Antología de la literatura fantástica, narra la premeditada venganza que una mariposa, a la que trató de apresar clavándole un alfiler en el cuerpo, emprende sobre ella. Cada día, cada vez que Kêng-Su vuelve a su habitación, encuentra, subrayadas con puntitos como de alfiler, en alguna de las páginas de los libros de su biblioteca, frases moralizantes e intimidatorias en la que se anuncia el castigo que la espera. Kêng-Su se obsesiona, no puede dejar de pensar en el animal: borda involuntariamente alas en el tapiz que le encargaron, durante las comidas sólo intenta conversaciones sobre insectos, ve las marcas de los puntitos en todas partes. Una mañana mientras está nadando en el mar ve aparecer a la mariposa con el alfiler todavía en el cuerpo, el insecto la asedia intentando incrustársela en los ojos. Kêng-Su nada con desesperación hasta la costa y logra salvarse. Sin embargo no puede desprenderse de la imagen temible que percibió en ese momento: la mariposa se transformó en un "fantasma", "un pequeño monstruo", cuyos ojos se superponen a los de ella cada vez que se mira al espejo. La secuencia prefigura la escena del desenlace, en la que la protagonista se ahoga intentando resistir a un nuevo ataque. El final queda previsiblemente a cargo de la segunda narradora, cuyo relato no sólo postula la duda acerca de la existencia del animal ("En la dorada claridad de la luna, Kêng-Su -afirma- hundía la cabeza en el agua y se alejaba de la costa. Luchaba contra un enemigo, para mí invisible." [24]), sino también la incertidumbre, algo más sorpresiva, de que todo lo narrado tenga una consistencia onírica. "Cuando pienso en Kêng-Su, -agrega la última frase- me parece que la conocí en sueño" (idem).

Con excepción de "Fragmentos de un libro invisible", que es el cuento menos de la predecible de la colección, todos los relatos de Autobiografia de Irene tienden a producir un impacto final. Contrarios a ese efecto de suspensión y de detenimiento que transmiten las historias de Viaje olvidado, estos argumentos buscan el desenlace sorpresivo que movilice la atención del lector y estimule la relectura. Mientras en las primeras narraciones de Ocampo el lector se inquieta, se desconcierta, se marea hasta perderse, persiguiendo un sentido que, por obra de una sustracción impensada (la de una conciencia lúcida que asuma a su cargo el significado de los hechos), se desvaneció para siempre, permanece esencialmente indeterminado, secreto e indefinido, en estos relatos el lector es inducido a un movimiento retrospectivo en el que reponer los significados nuevos y, por lo general, contradictorios que habilitan los finales múltiples. Además de la "rica y voluntaria ambigüedad" que Borges reconoció en las narra-

${ }^{12}$ Para el análisis específico de estos motivos en la narrativa de Ocampo, consultar Klingenberg (1987 y 1988) y Ulla (1981, 1992 y 1992a). 
ciones de Bianco, podría atribuirse a estos cuentos el mismo interés por el lector que celebró en Las ratas. La "improbable persona que lea estas páginas" a la que apela la narradora-protagonista de "Autobiografía de Irene" en el comienzo del relato ¿no recuerda acaso al "hipotético lector" de Delfín Heredia en Las ratas? Como en las narraciones de Bianco (sin dudas también en las de Bioy, menos, en las ficciones de Borges, donde la complicidad se frustra en el mismo momento en que se la propone), la figura de lector que modelan estos relatos es la de "un hombre silencioso cuya atención conviene retener, cuyas previsiones hay que frustrar, delicadamente, cuyas reacciones hay que gobernar y que presentir, cuya amistad es necesaria, cuya complicidad es preciosa." (Borges, 1944: 77). Un lector perspicaz e interesado, dispuesto a colaborar en desenlaces ambivalentes y enigmáticos, cuyos efectos finales lo reenvían a menudo al comienzo de la historia. Un lector distinto, más inteligente y menos perturbado que el que, atraído por la consternación en que viven los personajes de Viaje olvidado, retenido por la presión de lo indecible que atraviesa sus experiencias, se interesa menos en explicar el "enigma" que de los acontecimientos que en afirmar el "secreto" de sus voces. ${ }^{13}$

En "Autobiografia de Irene", la circularidad del relato es perfecta, el final de la historia coincide literalmente con el principio del cuento: la reiteración del párrafo inicial en el cierre de la narración impide la clausura definitiva e instaura un recomienzo incesante. Su complejidad temática y compositiva reúne gran parte de las estrategias y motivos explorados en el libro: final abierto, duplicidad de la instancia narrativa, atributo sobrenatural de la protagonista, reduplicación de los sucesos narrados (en visiones y hechos efectivos), postulación rigurosa del verosímil fantástico. Ejecutado con ostensible maestría narrativa y particular elegancia estilística (una elegancia similar a la que la escritura ocampiana presenta en la versión poética de esta historia ${ }^{14}$ ), "Autobiografía de Irene" concentra todas las cualidades necesarias para convertirse en un relato representativo de los mandatos borgeanos. No sorprende entonces que sea uno de los pocos cuentos de Ocampo que Borges reconoce sin reservas. ${ }^{15}$ La particularidad de la protagonista no sólo la liga a uno de sus más entrañables personajes de estos años (Irene Andrade es un doble invertido de Ireneo Funes), sino que además anticipa varias de las más célebres figuras ocampianas, con las que comparte el don de la clarividencia (con Aurora, la nena de "La sibila", con Leopoldina, con la nena sin nombre de "La muñeca", con Irma Riensi, el personaje principal de "La divina", con Porfiria Bernal, por mencionar algunas). La originalidad de la anécdota reside en que la involuntaria capacidad para prever el futuro priva a Irene de la facultad de recordar.

\footnotetext{
${ }^{13}$ Para la diferencia entre secreto y enigma, Blanchot (1962).

${ }^{14}$ Ocampo incluyó esta versión en Espacios métricos (Emecé, 1945).

${ }^{15}$ Ver Borges (2003).
} 
Comprendí entonces que perder el don de recordar - explica Irene- es una de las mayores desdichas, pues los acontecimientos, que pueden ser infinitos en el recuerdo de los seres normales, son brevísimos y casi inexistentes para quien los prevé y solamente los vive. El que no conoce su destino inventa y enriquece su vida con la esperanza de un porvenir que no sobreviene nunca: ese destino imaginado, anterior al verdadero, en cierto modo existe y es tan necesario como el otro. [...] Creo que esa falta esencial de recuerdos, en mi caso, no provenía de una falta de memoria: creo que mi pensamiento, ocupado en adivinar el futuro, tan lleno de imágenes, no podía demorarse en el pasado. (111)

Con el exceso de reflexión propio de estos narradores, la protagonista expone el motivo central del argumento. Convencida de que sólo con la llegada de la muerte podrá recuperar su pasado, vive aguardando "ese límite de vida que la acercar[á] al recuerdo" (117). Desde los quince años, desde el momento crucial en el que anticipó la muerte de su padre, ansía con fervor alcanzar ese instante de "dicha sobrenatural" (103). "¡Ah, cómo esperé penetrar, sin saberlo, en el claustral recuerdo de esos momentos! -exclama con ostensible amaneramiento poético. Con qué anhelo, sin saberlo, esperé la muerte, única depositaria de mis recuerdos." (113)

El presente de la narración coincide con la inminencia de la muerte de Irene, con los instantes previos en los que, impulsada por el temor de seguir viva y sin poder recordar, comienza paradójicamente a contar su autobiografía. El presagio final en el que desemboca su relato ilumina las razones que hacen posible que esta paradoja se realice. Como puntualizó Matilde Sánchez (idem: 279), es un cuento con trompe y'oeil. Una tarde sofocante, mientras Irene está sentada sola en un banco de la plaza, alguien se le acerca y empiezan a conversar. Hablan de la muerte, discuten los beneficios que la muerte le deparará a la protagonista, cuando, de pronto, la recién llegada le dice a Irene que cree conocerla desde hace tiempo, que ha visto su rostro en una fotografía que ella se sacó con un peinado alto, con cintas de terciopelo y sombrero con guindas. Se trata de la misma foto en la que Irene no reconoció su propia imagen y vio en cambio en su lugar a una mujer, sin sus imperfecciones, que había usurpado sus ojos, la postura de sus manos y el óvalo cuidadoso de su cara. La misteriosa aparición de la desconocida, a quien la protagonista se resiste a mirar y de quien no quiere saber el nombre, es el expediente narrativo, el truco, que permite que, aunque Irene no pueda recordar su pasado, su autobiografía se cuente de todas maneras. De la misma forma, abrupta e intempestiva, en que la interpela en el inicio del diálogo (todas las intervenciones de esta figura surgen, como ella misma en el desenlace del relato, de un modo inesperado), la desconocida anuncia su deseo de contar la vida de Irene. Mientras le pide que no lo haga, que la ayude a defraudar su destino incumpliendo lo que le está determinado, Irene ya sabe que ella la escribirá a pesar de todo: ve las páginas, ve la letra clara y vaticina entonces el comienzo del relato, que reproduce prolijamente el inicio de su autobiografía. La sentido de la narración se invierte por completo en este punto: el relato (imposible) que Irene ofrece de su vida no es sino su propia anticipación de lo 
que otra, una desconocida que parece conocer de ella lo que Irene no reconoce de sí misma, contará en su lugar.

La transformación, en cuyos efectos se leen las sospechas de Ocampo hacia las evidencias que fundan la escritura autobiográfica, afecta tanto el proceso enunciativo como la instancia temporal. Por un lado, la voz de la narradora-protagonista se identifica al mismo tiempo que se diferencia de esa desconocida (¿quién, sino su doble representado?) que asume a su cargo el relato de recuerdos que, aunque no le pertenezcan, sólo ella puede contar. Es interesante y significativo en este sentido que, tal como advirtió Annick Magin (1996, 81), Ocampo corrigiera, para la inclusión del cuento en el volumen de Sudamericana, la versión original de la escena que había aparecido en la publicación de Sur. En la edición de la revista, la imbricación de ambas voces aparece acentuada por la ausencia de marcas que las distingan. Todas las declaraciones se encuentran entrecomilladas, yuxtapuestas, sin guiones de diálogo y sin que se mencione la identidad de quien habla en cada caso. El conjunto de enunciados traduce gráficamente la proximidad de las voces. Por otro lado, en cuanto a la instancia temporal, la linealidad del relato se quiebra sorpresivamente, de modo tal que todo vuelve a empezar en el mismo punto en el que había quedado. Como el narrador-protagonista de $L a$ invención de Morel o como los Vermehren en El perjurio de la nieve, Irene queda atrapada en el círculo cerrado de la eterna repetición de lo mismo. ${ }^{16}$ Presa de sus adivinaciones, no puede de dejar de repetir el relato de acontecimientos vividos y olvidados. "El mundo es para ella una cárcel de previsiones que el presente corrobora infaliblemente" (Pezzoni, 1970: 475) Su destino se cifra en "vaticinar" el pasado o "recordar" el porvenir: retrospección y anticipación coinciden en el presente perpetuo de su autobiografía. El recuerdo sólo accede a su memoria bajo la forma de la premonición, reduplicado como adelanto de lo que ya pasó, así como el relato de su vida sólo puede contarlo una voz enigmática que, aún no siendo propia, tampoco puede ser completamente ajena. "¿Qué intercomunicación de clepsidra - pregunta González Lanuza $(1949,57)$, en la perspicaz reseña del libro que escribe para Sur- [...] se establece entre el destino de Irene y su supuesta "autobiógrafa"? Acaso sea la más recóndita de las revueltas enmarañadas de este claro y diáfano dédalo literario." El mérito máximo de este cuento ejemplar, sin dudas el más logrado de la colección, es haber dejado pendiente la respuesta a esta pregunta, más aún, es haber combinado con inigualable habilidad las obsesiones y recursos que inauguraron las narraciones de Borges y de Bioy, para escribir el cuento que anuncie, en las páginas de Sur, los límites de las convenciones autobiográficas, el carácter ficcional de toda autobiografía. Un mérito modesto para quien, sin proponérselo, había experimentado ya que la potencia de la ficción reside menos en la combinación de procedimientos complejos y temas prestigiosos, menos en la calculada y perfecta disposición de las unidades de la fábula, que en las secretas e imprevisibles relaciones que se establecen entre quien habla y lo

${ }^{16}$ Sobre el tópico del eterno retorno en los escritores de Sur, consultar Rivera (1972). 
que dice, entre la puerilidad de la anécdota narrada y el encuentro con lo desconocido que ella provoca en la voz que narra.

La sutil intuición de que las "imperfecciones" del comienzo anuncian logros más definitivos que los exitosos esfuerzos de Autobiografia de Irene le permitieron a González Lanuza señalar que, a pesar de la maestría que demuestra, la deliberación con que Silvina construye estos relatos traba el "juego inventivo de que [...] está dotada la autora" (idem: 58):

Lo que quiero decir -afirma en la conclusión de su comentario- es que, a mi entender, la capacidad literaria de Silvina Ocampo, más que organizadora de materiales dados, es directamente creadora de esos materiales; por eso obtiene sus mayores aciertos, no cuando compone, sino cuando realiza en sí misma el hallazgo de algo que parece rescatado de pronto de la tierra incógnita de los sueños.

Al tiempo que manifiesta el deseo de que la escritura de Silvina retome el camino de Viaje olvidado, su juicio valora con temprana lucidez los méritos de estos cuentos. Desatendiendo las normas establecidas por la prédica borgeana, González Lanuza advierte la "deliciosa fatalidad" que el esmerado aprendizaje compositivo de Silvina provocó en sus relatos. Con una marcada atención sobre sí misma, sobre las exigencias y demandas que se le presentan a su literatura, Silvina responde de manera eficaz al ideal de componer "invenciones rigurosas, verosímiles, a fuerza de sintaxis" (Bioy Casares, 1991: 11) y escribe entonces el más inteligente y legible de sus libros. Autobiografia de Irene prueba en este sentido lo que ella descubrirá poco después: que "la peor influencia que recibimos [...] es la de nosotros mismos" (Ocampo, 2008: 60), la que, volviéndola sensible a las determinaciones del contexto, la desvió de los hallazgos iniciales de sus primeros relatos. Anuncia además, en un movimiento compartido con la narrativa de Bioy, los límites de ese modelo de equilibrio constructivo, que la moral formalista reivindicó en el interior de Sur como una alternativa superadora de la falta de reflexión específica que caracterizaba al humanismo literario de la revista.

Junto a los cuentos de La trama celeste, la colección de Bioy que Sur publicó el mismo año que el libro de Ocampo, los relatos de Autobiografia de Irene participan del momento culminante en el que la máxima realización de los imperativos formales del relato coincide con la advertencia de su agotamiento perentorio. Con los cuentos de este libro, Bioy experimenta por primera vez una creciente incomodidad hacia las restricciones que le impone la moral narrativa de la que es no sólo uno de sus principales defensores sino también su representante más emblemático. La sospecha de estar componiendo, conforme a un oficio mecánicamente aprendido, narraciones de tramas cada vez más complejas e intrincadas motiva poco después un alejamiento relativo de las convenciones ejercitadas hasta ese momento. Con los cuentos de Autobiografía de Irene, Silvina ensaya, por su parte, técnicas y procedimientos de los que o bien se desprenderá luego por completo o bien incorporará transmutados a un universo literario propio, definitivamente alejado de los patrones del cálculo y la disciplina compositiva. 
La diferencia entre ambos reside en este sentido en las consecuencias dispares que este distanciamiento tendrá sobre sus ficciones posteriores. En el caso de Bioy, el recurso a la parodia como principal estrategia de revisión de los temas y las fórmulas técnicas desarrolladas mantiene su narrativa estrechamente ligada a una concepción constructiva de la literatura. Hasta el final suscribe a la idea de que las formas estéticas evolucionan conforme a un impulso interno de automatización, parodia y cambio. Con efectos cada vez menos sorprendentes y novedosos, Bioy ensaya durante más de cuatro décadas la renovación de un programa que su literatura había consolidado en los primeros libros. Los intentos repetidos por remozar ese programa, sumados a su persistente interés en alcanzar un "ideal de austeridad" (Pezzoni, 1986: 237) estilística y compositiva, transforman una obra que empezó siendo original en un literatura de magias modestas y alcances módicos. ${ }^{17}$ En el caso de Ocampo, por el contrario, el abandono o la transfiguración de las formas aprendidas es el resultado de un deslumbrante y demorado recomienzo de su literatura. Desde La furia y otros cuentos (1959), el último de sus libros que se editará en Sur, sus relatos retoman el movimiento inaugurado en Viaje olvidado y se apartan completamente de los valores, para entonces tradicionales y anacrónicos, que definen los criterios estéticos en la revista. Con voces nuevas, más cursis, más extravagantes, algo más vulgares, su narrativa inventa un mundo único, hecho, como advirtió Molloy (1978: 247), de "carpetas de macramé y medallas de la virgen de Luján", en el que una inocencia soberana -la que le sobreviene a estas voces cada vez que, desposeídas de sí mismas, hablan sin nada que ocultardespliega con una exaltación gozosa una repertorio de acontecimientos atroces y triviales a la vez.

\section{BIBLIOGRAFÍA}

AVARO, Nora.

2003 "La imaginación controlada". Texto leído en Homenaje a Silvina Ocampo. Feria de libro. Buenos Aires: Mimeo.

BLANCHOT, Maurice.

1969 "La vuelta de tuerca". El libro que vendrá. Caracas: Monte Ávila, pp. 143-151.

BIOY CASARES, Adolfo.

1991 "Prólogo", en Antología de la literatura fantástica. Buenos Aires: Sudamericana, pp. 4-11.

BORGES, Jorge Luis.

1944 "José Bianco: Las ratas (Buenos Aires, Sur, 1943)", Sur n 111, enero, pp.76-78.

\footnotetext{
${ }^{17}$ Para un desarrollo argumentado de estas conclusiones, consultar Podlubne (2004a).
} 
1985 "Prólogo", en Adolfo Bioy Casares, La invención de Morel. Buenos Aires: Seix Barral. [1940].

2003 "Autobiografía de Irene", El círculo secreto. Buenos Aires: Emecé Editores, pp. 210-211. Originalmente en Ocampo, Silvina. Autobiografia de Irene. Buenos Aires: Ediciones de Arte Gaglianone, 1982.

GONZÁLEZ LANUZA, Eduardo.

1949 "Silvina Ocampo: Autobiografía de Irene", Sur n 175, mayo, pp. $56-58$.

LOUIS, Annick.

2001 "Definiendo un género: La Antología de la Literatura Fantástica de Jorge Luis Borges, Adolfo Bioy Casares y Silvina Ocampo", Nueva Revista de Filología Hispánica, vol. XLIX, pp. 409-437.

LOUSTALT, Silvia y Eugenia STRACCALI.

2001 "Desde el otro cuarto. Otra mirada de Silvina Ocampo", en Fin(es) de siglo y Modernismo, tomo II. Comp. de M. Payeras Grau y L. Fernández Ripoll. Palma: Universitat de les Illes Balears, pp.733737.

MANGIN, Annick.

1996 Temps et écriture dans l'oeuvre narrative de Silvina Ocampo. Toulouse: Université du Tolouse-Le Mirail.

MOLLOY, Sylvia.

1969 "Silvina Ocampo, la exageración como lenguaje", Sur no 320, octubre, pp. 15-24.

1978 "La simplicidad inquietante en los relatos de Silvina Ocampo", Lexis 2, vol. 2, págs 241-251.

OCAMPO, Silvina.

1975 Autobiografia de Irene. Buenos Aires: Sudamericana.

2008 Ejércitos en la oscuridad. Buenos Aires: Sudamericana.

PANESI, Jorge.

2004 "El tiempo de los espejos: Silvina Ocampo", Orbis Tertius, no 10, pp. 93-100.

PERCAS, Helena.

1954 "La original expresión poética de Silvina Ocampo", Revista Iberoamericana, ${ }^{\circ} 38$, septiembre, pp. 283-298.

PEZZONI, Enrique.

1970 "Silvina Ocampo", en Enciclopedia de la literatura argentina. Comp. de Pedro Orgambide y Roberto Yahni. Buenos Aires: Sudamericana, pp. 473-76.

1986 "Silvina Ocampo: orden fantástico, orden social", en El texto y sus voces. Buenos Aires: Sudamericana, pp. 187-235. 
PODLUBNE, Judith.

2004 "La intimidad inconfesable en los cuentos de Silvina Ocampo", Orbis Tertius, $\mathrm{n}^{\mathrm{o}}$ 10, pp. 105-110.

2004 "Fantasía, oralidad y humor en Adolfo Bioy Casares", en El oficio que se afirma. Comp. Sylvia Saítta. Historia crítica de la literatura argentina, vol. 9. Buenos Aires: Emecé Editores, pp. 195-215.

KLINGENBERG, Patricia.

1987 "The Twisted Mirror: the fantastic stories of Silvina Ocampo", Letras Femeninas 1-2, vol. XIII, pp. 67-78.

1988 "The Mad double in the stories of Silvina Ocampo", Latin American Literary Review, $\mathrm{n}^{\circ} 32$, vol. XVI, julio-diciembre, pp. 29-40.

RIVERA, Jorge.

1972 "Lo arquetípico en la narrativa argentina del 40", en Nueva Novela Latinoamericana. Ed. de Jorge Lafforgue. Buenos Aires: Paidós, pp. 174-204.

SÁNCHEZ, Matilde.

1991 "Prólogo y notas", en Las reglas del secreto (antología). Buenos Aires: FCE.

TOMASSINI, Graciela.

1995 El espejo de Cornelia. La obra cuentística de Silvina Ocampo. Buenos Aires: Editorial Plus Ultra.

ULLA, Noemí.

1981 "Silvina Ocampo", en Historia de la literatura argentina. Buenos Aires: Centro Editor de América Latina, pp. 385-408.

1992 Invenciones a dos voces. Ficción y poesía en Silvina Ocampo. Buenos Aires: Torres Agüero Editores.

$1992^{a}$ "La fantasía en cuentos de Silvina Ocampo y su relación con otros textos hispanoamericanos", en El relato fantástico en España e Hispanoamérica. Ed. de Enriqueta Morillas Ventura. Madrid: Siruela, pp. 283-292. 